\title{
A method of mounting multiple otoliths for beam-based microchemical analyses
}

\author{
Christopher J. Donohoe • \\ Christian E. Zimmerman
}

Received: 2 November 2009 / Accepted: 22 June 2010/Published online: 13 July 2010

C The Author(s) 2010. This article is published with open access at Springerlink.com

\begin{abstract}
Beam-based analytical methods are widely used to measure the concentrations of elements and isotopes in otoliths. These methods usually require that otoliths be individually mounted and prepared to properly expose the desired growth region to the analytical beam. Most analytical instruments, such as LA-ICPMS and ion and electron microprobes, have sample holders that will accept only one to six slides or mounts at a time. We describe a method of mounting otoliths that allows for easy transfer of many otoliths to a single mount after they have been prepared. Such an approach increases the number of otoliths that can be analyzed in a single session by reducing the need open the sample chamber to exchange slides - a particularly time consuming step on instruments that operate under vacuum. For ion and electron microprobes, the method also greatly reduces the number of slides that must be coated with an electrical conductor prior to analysis. In this method, a narrow strip of cover glass is first glued at one end to a standard microscope slide. The otolith is then mounted in thermoplastic resin on the opposite,
\end{abstract}

\author{
C. J. Donohoe $(\bowtie)$ \\ Institute of Marine Sciences, \\ University of California, Santa Cruz, \\ 100 Shaffer Road, \\ Santa Cruz, CA 95060, USA \\ e-mail: cdonohoe@pmc.ucsc.edu \\ C. E. Zimmerman \\ U.S. Geological Survey, Alaska Science Center, \\ 4210 University Drive, \\ Anchorage, AK 99508, USA
}

free end of the strip. The otolith can then be ground and flipped, if needed, by reheating the mounting medium. After otolith preparation is complete, the cover glass is cut with a scribe to free the otolith and up to 20 small otoliths can be arranged on a single petrographic slide.

Keywords Otolith preparation · Throughput · Ion microprobe $\cdot$ Laser ablation $\cdot$ Thin section

\section{Introduction}

Beam-based analytical methods are widely used to measure the concentrations of elements and isotopes in otoliths (Campana 1999; Gillanders 2005; Elsdon et al. 2008). Commonly used methods include wavelength dispersive electron microprobe analysis (WD-EMPA), ion microprobe analyses such as proton-induced X-ray emission (PIXE) and secondary ion mass spectrometry (SIMS), and laser ablation inductively coupled plasma mass spectrometry (LA-ICPMS) (Campana et al. 1997; Weber et al. 2002; Morris et al. 2005; Donohoe et al. 2008). Beam-based methods are often favored because small beam diameters allow for high spatial resolution and can produce detailed chronologies of elemental and isotopic variation within specific otolith regions or over the life of a fish (Zimmerman and Reeves 2002; Elsdon et al. 2008).

Preparation of otoliths for beam-based analysis frequently requires sectioning or grinding followed by 
polishing. Although preparation is relatively simple, the need to individually mount and prepare each otolith can limit the sample analysis rate (sample throughput) on beam-based analyzers. The analytical beams on probe and laser ablation systems penetrate from a few to a few tens of micrometers into an otolith (Williams 1987). Consequently, each otolith must be individually mounted and carefully prepared to properly expose the region of interest (e.g., core) at the surface. Because most analytical instruments have sample holders that will accept only one to six slides or mounts, analysis of many otoliths typically requires repeated exchange of samples. Sample exchange can be time consuming, particularly on instruments that operate under vacuum and must re-equilibrate each time the sample chamber is opened. Further, because sample exchange is not automated, an operator must frequently attend to the instrument. Sample exchange can be reduced if several otoliths can be placed on each slide. Because each otolith must be prepared individually, mounting of multiple otoliths on a single slide can only be done after otoliths are sectioned and polished. Removing a prepared otolith from its mount, however, risks damage to the polished surface and may result in a shift in the mounting angle. Since some beam based methods, such as WD-EMPA, require a level surface with no scratches (de Pontual and Geffen 2002) such damage must be avoided.

In this paper, we describe a simple method of mounting otoliths that allows for individual preparation and then easy transfer of multiple otoliths to a single slide or mount for more efficient processing using beambased analyzers. The method does not disturb the original mount and therefore does not risk damaging or altering the angle of the otolith surface. Although this method has been described briefly in previous studies (e.g., Zimmerman and Reeves 2000) and similar methods may be in use, we present details of the method here to make it more widely available. By increasing the number of otoliths that can be loaded into the instrument, the total time and cost of beambased analyses can be reduced.

\section{Materials and methods}

The mounting method consists of three steps and makes use of cover glass as an intermediate base or foundation. To begin, cut a standard cover glass
(22 $\mathrm{mm}$ square) into narrow strips. Use a diamondtipped scribe to lightly score a line across the cover glass from edge to edge (Fig. 1a). A microscope slide or steel ruler can be used as a straightedge. Light score lines are best as these produce clean breaks. Score additional lines parallel to the first. Spacing between lines should be slightly wider than the otolith to be mounted. To break the cover glass, align a score line with the edge of a microscope slide (score line up) and bend free edge down to snap into strips.

Next, mount a strip of cover glass to a standard $(25 \mathrm{~mm} \times 75 \mathrm{~mm})$ microscope slide. Use a small amount of thermoplastic resin (e.g., Crystalbond 509) or cyanoacrylate glue to attach one end of the strip to the slide; the opposite end should remain free (Fig. 1b). Position the strip about $5 \mathrm{~mm}$ from the end of the slide to prevent the strip (and mounted otolith) from hitting the dividers in the slide storage box during the preparation process.

Third, mount a whole or sectioned otolith in thermoplastic resin on the free end of the cover glass strip. Heat the prepared slide and a reservoir of thermoplastic resin on a hotplate. Place the otolith on the slide to warm before mounting; this will reduce the formation of bubbles in the thermoplastic resin. Transfer a small amount of resin to the free end of the glass strip, and then transfer the otolith into the resin. After the slide has cooled, use the scribe to etch the sample number into the glass strip near the otolith (Fig. 1c). This allows the otolith to be identified while in the analyzer. The mounted otolith can now be sanded and polished as usual to expose the desired growth regions (Fig. 1d). If needed, the otolith can be flipped and prepared on the opposite side by reheating the mounting medium.

After the otoliths have been prepared, several can be transferred to a single analytical slide or mount for later microchemical analysis. Use the diamond-tipped scribe to lightly score a line across the cover glass strip to cut the otolith free of the preparation slide (Fig. 1e). Use forceps to transfer the glass rectangle and otolith to the analytical mount and glue in place with cyanoacrylate glue (Fig. 1f). Apply glue in a well-ventilated area to prevent glue vapors from depositing on the otolith surface. Otoliths can be transferred to analytical mounts of any size, but sample holders on most instruments accept either petrographic slides $(25 \mathrm{~mm} \times 45 \mathrm{~mm})$ or $25 \mathrm{~mm}$ rounds (glass or epoxy). These two mounts can 
Fig. 1 To mount otoliths for beam-based microchemical analysis, a score a standard cover glass with a diamond-tipped scribe to slice into strips, $\mathbf{b}$ attach one end of the glass strip to a standard microscope slide, c mount otolith in thermoplastic resin on free end of glass strip, d sand and polish to expose growth history, e score the glass strip to cut and free the otolith and mount from slide, then $\mathbf{f}$ transfer to the analytical slide or mount and affix with cyanoacrylate glue. Petrographic slides g can hold up to 20 small (3 $\mathrm{mm}$ ) otoliths while $25 \mathrm{~mm}$ rounds $\mathbf{h}$ can hold up to 15 otoliths
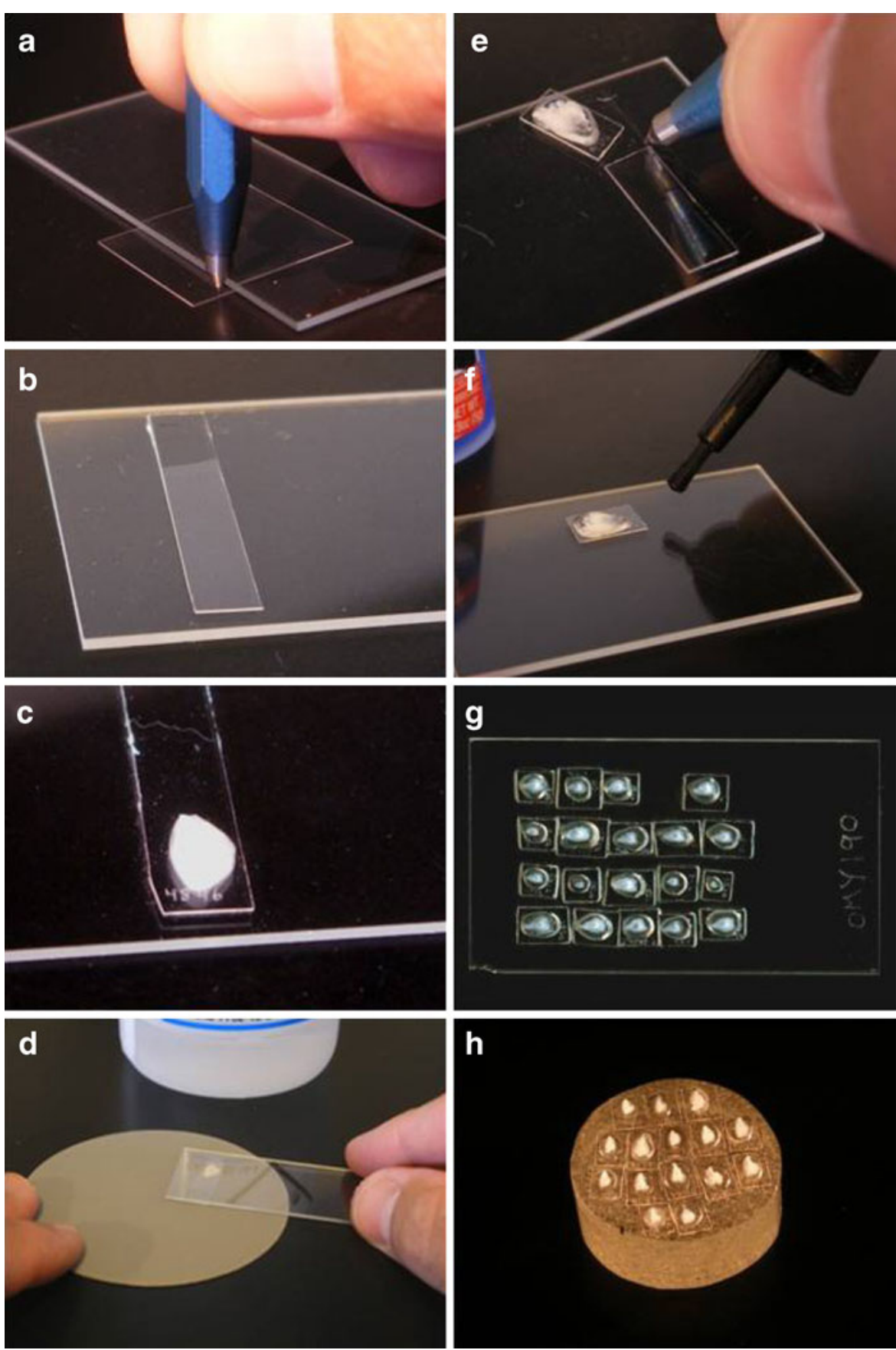

accommodate 20 and 15 small ( $3 \mathrm{~mm}$ long) otoliths, respectively (Fig. $1 \mathrm{~g}$ and $\mathrm{h}$ ). To release an otolith from the analytical mount (e.g., to remount for reanalysis), apply a small amount of distilled water to the edge of the cover glass to soften the cyanoacrylate glue.

\section{Discussion}

Our method of mounting otoliths on narrow strips of cover glass allows for easy transfer of otoliths after they have been individually prepared for microchemical analysis. This approach can be used to 
increase the number of otoliths that can be inserted into beam-based analyzers, reducing the need to open the sample chamber to exchange slides and thereby increasing sample throughput. The increase in sample throughput will depend on the number of otoliths that can fit on each analytical mount and on instrument design. The largest gains in throughput can be expected for instruments that operate under vacuum and take a long time to equilibrate after a sample exchange. For example, complete exchange of a set of four petrographic slides on the Cameca SX-100 electron microprobe takes $15 \mathrm{~min}$. Mounting 12 otoliths per slide (rather than one) eliminates 11 sample exchanges resulting in a direct savings of approximately $3 \mathrm{~h}$ of instrument time. On the micro-PIXE instrument at the University of Guelph, it takes approximately $30 \mathrm{~min}$ to replace a set of three $25 \mathrm{~mm}$ round mounts holding about 24 otoliths and to re-establish vacuum (J.L. Campbell, Univ. of Guelph, pers. comm.). At Guelph, several otolith sections are embedded in each mount prior to polishing to increase sample throughput. Sample exchange can be faster for laser ablation units used with ICP-MS because the units are not operated at vacuum. These systems however must be completely purged of atmospheric gases before detectors on the ICP-MS return to background levels and analysis can resume. This process may take as little as $5 \mathrm{~min}$ but may take up to $30 \mathrm{~min}$ on some multi-collector ICP-MS analyzers (C. Donohoe, unpubl. data).

More importantly, reducing or eliminating sample exchanges allows some beam-based instruments to run unattended for extended periods. On instruments with computer-controlled stages, analysis coordinates can be stored for all otoliths in the sample chamber, and then set to run without input from an operator, reducing operator fatigue. On the Cameca SX-100 electron microprobe, we routinely set coordinates for 50-60 spot analyses on 48 otoliths at the start of an analytical session, and then let the instrument run unattended for up to several days. The Guelph microPIXE instrument can also perform unattended analysis of all otoliths in the sample chamber, though continuous line scans perpendicular to the growth annuli are preferred to spot analyses (J.L. Campbell, Univ. of Guelph, pers. comm.). Laser ablation units used with ICP-MS can also store analysis coordinates, but the units we have used were not fully integrated with the ICP-MS and analysis required an operator to attend the instrument. In addition, for proton and electron microprobes, mounting several otoliths on a single mount also greatly reduces the number of mounts that must be coated with an electrical conductor prior to analysis.

One crucial step before transferring multiple otoliths to the analytical mount is to determine if the instrument design restricts where otoliths can be placed on the mount. For example, it may be necessary to leave a few millimeters of free space along the edges of a petrographic slide so it can slip into the appropriate tracks in the sample holder. On some instruments, the travel of the sample holder may be limited such that the corners or edges of the mount cannot be targeted by the analytical beam, while on others the corners cannot be viewed in transmitted light. A second concern is that mounting otoliths on a cover glass raises the surface of the otolith an additional 200-300 micrometers above the surface of the analytical mount, possibly beyond the focal range of the instrument. This added height is not a problem if the vertical position of the mount can be adjusted in the sample holder, such as with many round mounts. If the vertical position is fixed, the sample holder may need to be modified. Finally, our mounting method results in gaps between otoliths and a non-flat sample surface and may not be suitable for SIMS instruments.

In conclusion, our method of mounting otoliths on narrow strips of cover glass requires additional time over direct mounting, but this cost is small compared to the amount of instrument time that can be saved when performing beam-based microchemical analyses. While this method is focused on otoliths, it can potentially be used for other small biological or geological samples.

Acknowledgements We thank Roger Nielsen for discussions and guidance during the development of this technique. Any use of trade, product, or firm names is for descriptive purposes only and does not imply endorsement by the U.S. Government.

Open Access This article is distributed under the terms of the Creative Commons Attribution Noncommercial License which permits any noncommercial use, distribution, and reproduction in any medium, provided the original author(s) and source are credited.

\section{References}

Campana SE (1999) Chemistry and composition of otoliths: pathways, mechanisms, and applications. Mar Ecol Prog Ser 188:263-297 
Campana SE, Thorrold SR, Jones CM, Gunther D, Tubrett M, Longerich H, Jackson S, Halden NM, Kalish JM, Piccoli PM, de Pontaul H, Troadec H, Panfili J, Secor DH, Severin KP, Soey SH, Thresher R, Teesdale WJ, Campbell JL (1997) Comparison of accuracy, precision, and sensitivity in elemental assays of fish otoliths using the electron microprobe, proton-induced X-ray emission, and laser ablation inductively coupled plasma mass spectrometry. Can J Fish Aquat Sci 54:2068-2079

de Pontual H, Geffen AJ (2002) Otolith microchemistry. In: Panfili J, de Pontual H, Troadec H, Wright PJ (eds) Manual of fish sclerochronology. Ifremer-IRD, Brest, pp 243-302

Donohoe CJ, Adams PB, Royer CF (2008) Influence of water chemistry and migratory distance on ability to distinguish progeny of sympatric resident and anadromous rainbow trout (Oncorhynchus mykiss). Can J Fish Aquat Sci 65:10601075

Elsdon TS, Wells BK, Campana SE, Gillanders BM, Jones CM, Limburg KE, Secor DH, Thorrold SR, Walther BD (2008) Otolith chemistry to describe movements and life-history parameters of fishes: Hypotheses, assumptions, limitations and inferences. Oceanogr Mar Biol: An Annu Rev 46:297-330
Gillanders BM (2005) Otolith chemistry to determine movements of diadromous and freshwater fish. Aquat Living Resour 18:291-300

Morris JA, Rulifson RA, Babaluk JA, May PG, Campbell JL (2005) Use of micro-PIXE to investigate otolith $\mathrm{Sr}$ distributions of the anadromous striped bass, Morone saxatilis. X-Ray Spectrom 34:301-305

Weber PK, Hutcheon ID, McKeegan KD, Ingram BL (2002) Otolith sulfur isotope method to reconstruct salmon (Oncorhynchus tshawytscha) life history. Can J Fish Aquat Sci 59:587-591

Williams KL (1987) An introduction to X-ray spectrometry: $\mathrm{X}$-ray fluorescence and electron microprobe analysis. Allen and Unwin, London

Zimmerman CE, Reeves GH (2000) Population structure of sympatric anadromous and nonanadromous Oncorhynchus mykiss: evidence from spawning surveys and otolith microchemistry. Can J Fish Aquat Sci 57:2152-2162

Zimmerman CE, Reeves GH (2002) Identification of steelhead and resident rainbow trout progeny in the Deschutes River, Oregon revealed with otolith microchemistry. Trans Am Fish Soc 131:986-993 